\title{
Which Drug For Which Patient? Is There a Fluoxetine Responding Versus a Bupropion Responding Personality Profile?
}

\author{
D. Stewart Bell ${ }^{\mathrm{a},}$, W. Mark Shipman ${ }^{\mathrm{b}, *}$, Mario A. Cleves ${ }^{\mathrm{c}}$ and Jill Siegelman ${ }^{\mathrm{d}}$ \\ ${ }^{a}$ Ontario Mental Health Department, Kaiser Permanente, Fontana Medical Center, Ontario, CA United States \\ ${ }^{b}$ University of California, San Diego, San Diego, CA United States \\ ${ }^{c}$ Department of Biostatistics, UAMS College of Medicine, Little Rock, AR, United States \\ ${ }^{4}$ Private Practice, Carlsbad, CA, United States
}

\begin{abstract}
This paper proposes that a certain premorbid personality type - that of hard driving, achievement-oriented, often exercise-oriented individuals - correlates with bupropion response; conversely, patients without these premorbid traits and whose depression is marked by mood swings, irritability and rumination are likely fluoxetine responders.

The authors developed the Fluoxetine Bupropion Assessment Scale (FBAS), a 10-question, self-administered rating scale, to assess these traits and hypothesized that its use would improve outcomes.

A Marriage and Family Therapist (MFT) and a Registered Nurse/Nurse Practitioner (RN/NP) retrospectively reviewed 72 charts from one psychiatrist's office for two time periods: before and after the psychiatrist utilized the questionnaire to guide antidepressant selection (33 charts before and 39 charts after). Raters were blinded to the theory and to the treatment time period. On the basis of clinical information in the charts, they formulated Clinical Global Impression assessments of treatment response in patients with Beck Depression Inventory scores $\geq 17$ who were not on either drug at the time of intake, and who were prescribed either fluoxetine or bupropion.

The data were in the direction of better results in the FBAS-guided group, particularly after adjusting for age, gender and marital status (efficacy $\mathrm{p}=0.087$ ). When global improvement data were combined into three groups describing treatment response (improved, minimal to no improvement, and worse) there were statistically significant better results $(p=0.047)$ in the FBAS-guided treatment group. Revision and validation of the questionnaire and a larger, randomized study seem indicated.
\end{abstract}

Keywords: Bupropion, depression, exercise, fluoxetine, personality, rating scale, selective serotonin reuptake inhibitor, temperament.

\section{INTRODUCTION}

Which drug for which patient? Because a patient must wait weeks - according to some studies upwards of 12 weeks $[1,2]$ - for an antidepressant to be effective for unipolar depression, and because the initial drug prescribed often benefits only about $50-70 \%$ of patients $[3,4]$, many patients continue to suffer from depression for significant time periods while waiting for an effective drug to be found.

Current bases upon which the choice of an initial antidepressant is made include cost, side effect profiles, propensity for drug interactions, availability on formularies, physician preferences, severity of depression $[5,6]$, presence of psychotic features [7] and presence of a comorbid condition, such as Attention-Deficit Hyperactivity Disorder (ADHD), Obsessive Compulsive Disorder (OCD), and certain anxiety

*Address correspondence to this author at Psychiatry, Kaiser Permanente, 3330 Centrelake Drive, Ontario, CA 91761, United States;

Tel: (866) 205-3595; Fax: (909) 974-4701;

E-mail: Dwight.S.Bell@kp.org

${ }^{* *}$ Deceased or substance abuse disorders [8-11]. Although physicians do consider certain symptoms reported by patients in selecting among antidepressants, usually the quality of the depression and the premorbid personality of the patient are not factors in drug selection.

There is currently no brief, office-based rating instrument designed specifically to determine which antidepressant medication should be given to which patient.

This paper proposes that patients who are particularly likely to respond to bupropion have certain premorbid personality characteristics. They are hard-driving, "highpowered" individuals, often entrepreneurs or successful business people, who relate to life in terms of accomplishments and achievements. They commonly report that their mood improves with exercise. The description of their depression is highly energy-related.

By contrast, it is observed that patients who are most likely to respond to fluoxetine have different premorbid characteristics. They rarely report exercise as meaning much to them, either in their premorbid state or when depressed, 
and their depression is not as connected with the notion of body movement. They do not relate to life in terms of accomplishments to the same degree as do bupropion responders. In addition to a different premorbid history, the fluoxetine-responding patients describe their depression with a different cluster of symptoms. When they present for treatment, their depression has more "darkness" associated with it, more moodiness, more swings in mood, and they "cling" more. Increased irritability is often prominent. Ruminating more often than bupropion responders, they often ask questions such as, "How do I get out of this?" or state, "I see no way out of this."

The premise of this paper is that bupropion-responding patients report depression in a characteristic way and selective serotonin reuptake inhibitor (SSRI)-responding patients report depression in a characteristic way, and the two ways are different. The bupropion-responding patients say, "I've lost energy. I can't focus. I'm scattered. My attention is easily distracted. My old drive and purpose aren't there." These patients often report a loss of something - of drive, of purpose.

The above traits and symptoms are not reported to the same degree in SSRI-responding patients, who seem to "fall into" something. The SSRI-responding patients often describe weepiness, mood changes, irritability, darkness, being "up and down," "being in a pit," and self-esteem difficulties.

Not all patients presenting for treatment of unipolar depression may be categorized as described, and many patients respond to either SSRIs or to bupropion. The authors have noticed clinically, however, that when patients can be categorized as SSRI or bupropion responders, the patients' response to medication is more predictable and more complete, and the medication for that category becomes the drug of choice.

This paper proposes using personality traits - not personality disorders per se - to guide antidepressant selection. It identifies two characteristics that predispose to bupropion response - achievement orientation and history of response of mood to exercise. The achievement orientation category is similar to the premorbid personality described by Akiskal [12], as "hyperthymic temperament," which he described as "very successful, eminent people ... who run the world" [13]. Akiskal describes these patients as over-talkative, extroverted, over-involved, uninhibited, "full of plans," overconfident, irritable, cheerful, over-optimistic, exuberant, meddlesome and promiscuous [12]. The hyperthymic temperament, which is described as including habitual short sleep (often three to four hours per night), seems much closer to hypomania or mania than are the traits described in this paper, however.

The characteristic personality type associated in this paper with fluoxetine response is similar to the "depressive personality" described by various clinicians [14]. Chronic pessimism, loneliness, dissatisfaction, guilt, feelings of inadequacy, and certain other characteristics common in "depressive personality" and chronic low-level depression may describe a more serotonergic subgroup of this disorder. Ravindran, et al [15] reported that "subaffective dysthymia," a chronic depressive syndrome described by Akiskal, seems to respond well to fluoxetine, which is similar to the authors' findings. Kramer [16] believes that rejection sensitivity responds to fluoxetine, which also coincides with this report.

There are similarities between the above observations of bupropion-responding patients and Bipolar II patients. However, the hypomanic episode required for diagnosis of Bipolar II disorder is described as an "unequivocal change in functioning that is uncharacteristic of the person when not symptomatic" in DSM 4-TR [17], in contrast to this paper's describing long-term traits.

The premorbid high-energy level that this paper associates with bupropion response has some similarity to ADHD. This paper is not, however, simply promoting better diagnosis of ADHD, as it reports other traits predicting bupropion response, such as exercise response. Furthermore, the authors observe that many bupropion responders in their premorbid condition, in contrast to ADHD patients, were highly focused; it is only in their depressed state that these patients experienced impaired concentration.

\section{MATERIALS AND METHODOLOGY}

One author (DSB) developed a 10-question, selfadministered rating scale, the Fluoxetine Bupropion Assessment Scale (FBAS), to further assess these traits and the observed correlation. After the scale had been utilized to guide treatment in one author's practice for several years, it was decided to retrospectively review charts in this psychiatrist's practice to see if use of the scale had improved patient outcomes. It was hypothesized that use of the FBAS by a psychiatrist to select an antidepressant for patients had improved treatment outcomes.

In the scale, questions 1-5 evaluated traits which were hypothesized to predict bupropion response. The first two questions examined the importance of exercise in the predepressed state and mood response to exercise. While exercise has health benefits for most patients, only some individuals report an "endorphin release" or mood benefit from exercise, while others simply feel tired afterward. This paper postulates that exercise-responding patients are biochemically different and are likely to respond to bupropion, possibly because bupropion causes a mild increase in dopamine and norepinephrine, neurotransmitters which increase during exercise [18]. In the scale, questions 3 and 4 were designed to assess achievement orientation; question 5 asked about hyperactivity, which could include either ADHD, which in some studies has shown a limited response to bupropion treatment $[19,20]$ or simply pre-depression high energy, which the authors also postulate is associated with bupropion response.

Questions 6-10 assessed symptoms of depression hypothesized to indicate fluoxetine response: rumination, feelings of "darkness", tendency to "cling" to others, or a feeling that other people do not meet one's interpersonal needs. Because the authors describe the fluoxetine-responding traits more as rumination than as hopelessness per se, the issue of hopelessness was not addressed in this scale. Not all postulated fluoxetine-responding traits could be included in a scale of this brevity - self-esteem difficulties and irritability were not assessed. 
For ease of scoring, the questions were designed so that low numerical answer scores (0-2.5) would indicate fluoxetine response, and high scores (3-5) would indicate bupropion response. Thus, for some questions, the answer, "A great deal" would score "5," and on other questions, "Not much" would score "5."

Charts for this retrospective study were screened by clerical staff at the outpatient office of one author (DSB). Office staff created lists of patients seen during two time periods - one before the psychiatrist was informed of the above-stated theory by another author (WMS), and the other after he was informed of the theory, developed the FBAS, and began administering and using it to guide treatment.

Staff utilized scheduling books, accounting records, and examination of current and stored charts to create a sequential list, in order seen at the office, for each of the time periods, to obtain approximately 50 sequentially seen charts for each time period.

Inclusion criteria included outpatients with depressive spectrum illnesses (Major Depression or Depression NOS) with Beck Depression Inventory scores $\geq 17$, who were prescribed fluoxetine or bupropion as the initial drug prescribed by the psychiatrist. Patients with intake diagnoses of schizophrenia, bipolar disorder, obsessive compulsive disorder, or panic disorder were excluded from the study, as were patients with substance abuse in the two months prior to intake, and patients assessed to have depression due to a medical condition. Patients were excluded who had received fluoxetine or bupropion at any time prior to initial evaluation, or who had received any antidepressant treatment in the two months prior to their initial evaluation. After the abovementioned exclusions, there were 33 patients in the nonFBAS group, of whom $42.4 \%$ were male, with a mean age of 33.8 years. In the FBAS-guided treatment group were 39 patients, $56.4 \%$ male, with a mean age of 30.4 years. Charts meeting criteria were photocopied and prepared so that the reviewers were blinded as to the time period involved. All patient identifiers were removed. The reviewers were not informed of the hypothesis being tested.

Raters reviewed charts using Clinical Global Impression (CGI) criteria to assess severity of illness, drug efficacy (therapeutic effect / side effect) and global improvement from clinical information in the charts. The CGI rates treatment response as 0-not assessed, 1-very much improved, 2much improved, 3-minimally improved, 4-no change, 5minimally worse, 6- much worse, 7-very much worse.

Intent-to-treat analysis was used based on 72 observations. Analysis was performed to determine if the physician utilized the FBAS score for drug allocation during the FBAS-guided treatment phase. Logistic regression was used to model drug allocation on each FBAS item independently and on all items in a stepwise approach using a best-subset selection method [21]. Ordered logistic regression was used to model medication efficacy and degree of global improvement on intervention strategy. Because of the small number of patients in each CGI cell, the data were further analyzed by combining treatment responses into three larger groups by CGI score: good response (1-2), minimal to no improvement (3-4), and worse (5-7).
It was hypothesized that individuals scoring high on the bupropion-oriented questions 1-5 would score low on the fluoxetine-oriented questions 6-10, and vice-versa. To determine if the questionnaire did identify two separate groups of depressed patients, the two domains (1-5 and 6-10) were labeled and dichotomized as high or low based on the average score, and cross-tabulated. The median score of the two groups was also used to dichotomize the two groups.

The data were coded for this analysis the same way as in the questionnaire, in that a patient's strong endorsement of fluoxetine items results in a low numerical score on fluoxetine items, and a patient's strong endorsement of bupropion items results in a high score on bupropion items. Therefore, a high total score on the questionnaire was postulated to predict bupropion response and a low total score, fluoxetine response.

\section{RESULTS}

Total FBAS was a strong predictor $(\mathrm{p}=0.017)$ of treatment allocation, indicating that the physician did utilize the scale to determine which medication to prescribe.

The evidence is in the correct direction, but the data do not provide sufficient evidence at the 5\% level to support the hypothesis that FBAS-guided treatment allocation improves patient outcome as measured by efficacy or global improvement $(\mathrm{p}=0.175$ and $\mathrm{p}=0.128$, respectively).

However, the odds that a patient receiving FBAS-guided treatment had a higher efficacy score were $76 \%$ greater than for a patient receiving a non-FBAS-guided treatment. Similarly, the odds that a patient receiving FBAS-guided treatment had a greater global improvement score were $92 \%$ greater than for a patient receiving non-FBAS-guided treatment (Table 1).

Similar results were obtained after adjusting for severity of illness (efficacy $p=0.139$, global improvement $p=$ $0.147)$, and for differences in age, gender, and marital status (efficacy $\mathrm{p}=0.087$, global improvement $\mathrm{p}=0.122$ ).

When global improvement was reclassified into three groups based on the score: (1-2, 3-4, and 5-7), the FBASguided treatment group had a statistically significant improvement compared to the non-FBAS-guided treatment group, at the $5 \%$ level $(\mathrm{p}=0.047)$.

To evaluate if the questionnaire identified two separate groups, an analysis was performed for both the average and median trait scores for questions 1-5 (bupropion-responding personality style) and questions 6-10 (fluoxetine-responding personality style). These results are shown in Table 2 (for average trait score) and in Table $\mathbf{3}$ (for median trait score).

\section{DISCUSSION}

This is a preliminary study, designed to see if an easily administered questionnaire based on premorbid traits and certain depressive symptoms could "improve the aim" of a psychiatrist in selecting an antidepressant. The data were in the direction of better results in the FBAS-guided group, particularly after adjusting for differences in age, gender, and marital status. When global improvement data were grouped, there were statistically significant better results in the FBASguided group. 
Table 1. Odds Ratio and 95\% Confidence Interval for the Association of FBAS-guided Treatment with Efficacy and Global Improvement

\begin{tabular}{|c|c|c|c|}
\hline & Odds Ratio & $\mathbf{9 5 \%}$ Confidence Interval & p-value \\
\hline \hline Efficacy & 1.760 & 0.778 to 3.985 & 0.175 \\
\hline Global Improvement & 1.922 & 0.828 to 4.463 & 0.128 \\
\hline
\end{tabular}

Table 2. Number of Patients Stratified as High or Low Based on Average Trait Scores

\begin{tabular}{|c|c|c|c|c|}
\hline & & \multicolumn{2}{|c|}{$\begin{array}{l}\text { Average Bupropion-Oriented Traits Score } \\
\text { (Questions 1-5) }\end{array}$} & \multirow[t]{2}{*}{ Tota } \\
\hline & & 0 to $<3$ & $\geq 3$ & \\
\hline \multirow{2}{*}{$\begin{array}{l}\text { Average Fluoxetine-Oriented Traits Score } \\
\text { (Questions 6-10) }\end{array}$} & $0-2.5$ & 13 & 13 & $26^{2}$ \\
\hline & $>2.5$ & 8 & 1 & $9^{3}$ \\
\hline \multicolumn{2}{|l|}{ Total } & $21^{1}$ & 14 & 35 \\
\hline
\end{tabular}

1. Of the 21 individuals that scored low $(<3)$ in the Bupropion-Oriented traits score, $13(61.9 \%)$ scored low $(0-2.5)$ in the Fluoxetine-Oriented traits score $(p=0.3833)$.

2. Of the 26 individuals that scored low $(0-2.5)$ in the Fluoxetine-Oriented traits score, $13(50.0 \%)$ scored low $(<3)$ in the Bupropion-oriented traits score $(\mathrm{p}=1.0000)$.

3. Of the 9 individuals that scored high $(>2.5)$ in the Fluoxetine-Oriented traits score, one $(11.1 \%)$ scored high $(>3)$ in the Bupropion-Oriented traits score $(p=0.0391)$.

Table 3. Number of Patients Stratified as High or Low Based on Median Trait Scores

\begin{tabular}{|c|c|c|c|c|}
\hline & & \multicolumn{2}{|c|}{$\begin{array}{c}\text { Median Bupropion-Oriented Traits Score } \\
\text { (Questions 1-5) }\end{array}$} & \multirow[t]{2}{*}{ Total } \\
\hline & & 0 to $<3$ & $\geq 3$ & \\
\hline \multirow{2}{*}{$\begin{array}{l}\text { Median Fluoxetine-Oriented Traits Score } \\
\text { (Questions 6-10) }\end{array}$} & $0-2.5$ & 9 & 17 & $26^{2}$ \\
\hline & $>2.5$ & 6 & 3 & $9^{3}$ \\
\hline \multicolumn{2}{|l|}{ Total } & $15^{1}$ & 20 & 35 \\
\hline
\end{tabular}

1. Of the 15 individuals that scored low $(<3)$ in the Bupropion-Oriented traits score, $9(60.0 \%)$ scored low $(0-2.5)$ in the Fluoxetine-Oriented traits score $(\mathrm{p}=0.6072)$.

2. Of the 26 individuals that scored low $(0-2.5)$ in the Fluoxetine-Oriented traits score, $9(34.6 \%)$ scored low $(<3)$ in the Bupropion-oriented traits score $(\mathrm{p}=0.1686)$.

3. Of the 9 individuals that scored high $(>2.5)$ in the Fluoxetine-Oriented traits score, three $(33.3 \%)$ scored high $(>3)$ in the Bupropion-Oriented traits score $(\mathrm{p}=0.5078)$.

The analysis for internal consistency, designed to evaluate if the questionnaire identified two different subgroups of patients, did not show that the questionnaire differentiated the two hypothesized groups, perhaps due to small sample size. Sample size was not sufficient to determine which individual questions were driving the overall tendency of the questionnaire to predict bupropion versus fluoxetine response.

Some of the ten scale questions - numbers 4 and 5 in particular - may identify undiagnosed bipolar patients. This seems unavoidable, as traits of bipolar disorder overlap traits of other diagnostic categories, including personality disorders.

\section{CONCLUSION}

Since this study was performed, the scale has been revised to better assess premorbid traits. The revision also assesses irritability and self-esteem, and quantifies exercise participation prior to the onset of depression.
The study was limited by the modest sample size, which diminished the statistical power to test the hypotheses related to efficacy and global improvement. The scale in this study has not been validated. Studies to validate the scale (with Akiskal's Temps-A or Cloninger's TCI) and a larger study initially randomized to treatment protocol, with subsequent randomization to fluoxetine and bupropion treatment in the non-FBAS-directed group, are indicated. Replication of the study with a larger sample could better inform the relationship of FBAS-guided treatment with efficacy and global improvement. If these results are positive, the use of a brief, easily administered, office-based questionnaire could increase the likelihood that physicians will select the optimum antidepressant for patients, thus speeding patients' recovery from depression.

\section{CONFLICT OF INTEREST}

The authors confirm that this article content has no conflicts of interest. 


\section{FLUOXETINE - BUPROPION ASSESSMENT SCALE (FBAS)}

After reading each question carefully, please circle the number corresponding to the answer which best describes your experience:

1. Before I became depressed, exercise was important to me to the following degree:

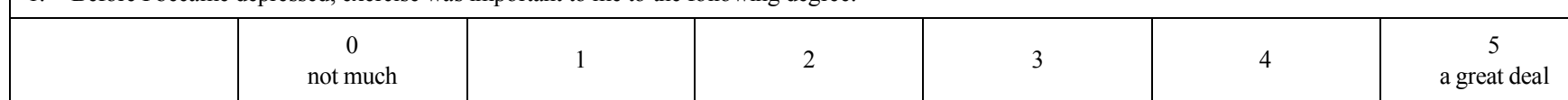

2. When I have exercised, it made a difference in my mood:

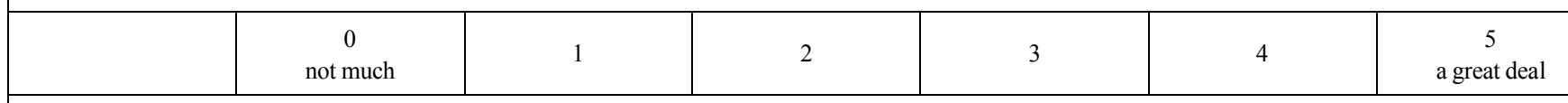

3. The extent to which I relate to life in terms of accomplishments and achievements is:

\begin{tabular}{|c|c|c|c|c|c|c|}
\hline & 0 & 1 & 2 & 3 \\
not much & a great deal & & & \\
\hline
\end{tabular}

4. Prior to my depressive episode I was an "entrepreneurial personality" (someone who enjoys organizing and taking the risks of a new business):

\begin{tabular}{|c|c|c|c|c|c|c|}
\hline & 0 & 1 & 2 & 3 \\
not much & a great deal & & & \\
\hline
\end{tabular}

5. I have been described as hyperactive either now or in the past:

\begin{tabular}{|c|c|c|c|c|c|c|}
\hline & 0 & 1 & 2 & 3 \\
not much & a great deal & & & \\
\hline
\end{tabular}

6. With regards to my depression:

\begin{tabular}{|c|c|c|c|c|c|c|}
\hline & $\begin{array}{c}0 \\
\text { there are large } \\
\text { swings in my mood }\end{array}$ & 1 & 2 & 5 \\
my depression stays \\
constant
\end{tabular}

7. I get "stuck" on thoughts - especially negative ones - and find it difficult to get them out of my mind:

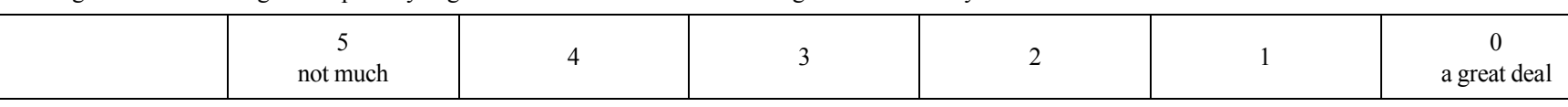

8. The degree of "darkness" - the degree that things seem black - that I feel when I am depressed is:

\begin{tabular}{|c|c|c|c|c|c|c|}
\hline & $\begin{array}{c}5 \\
\text { not much }\end{array}$ & 4 & 3 & 2 & 2 \\
\hline
\end{tabular}

9. I feel that my interpersonal needs are not being met by others:

\begin{tabular}{|c|c|c|c|c|c|c|}
\hline & 5 & 4 & 3 & 2 & 2 \\
not much & a great deal & 3 & 1 \\
\hline
\end{tabular}

10. I consider myself a perfectionist - it is very important to me that details of my work be done precisely right:

\begin{tabular}{|c|c|c|c|c|c|}
\hline & 5 & 4 & 3 & 2 & 0 \\
& not much & a great deal & & 2 \\
\hline
\end{tabular}

\section{ACKNOWLEDGEMENTS}

One of the authors, W. Mark Shipman, MD, died during the preparation of this study. The authors wish to thank Maher S. Kozman MD, George B. Bell, Carl Shubbs PhD, and Johanna Walthall $\mathrm{PhD}$ for their contributions to this article.

Some of the data presented in this article were presented as a poster at the 2003 American Psychiatry Association meeting, San Francisco, CA.

\section{REFERENCES}

[1] Georgotas A, McCue RE, Cooper TB, Nagachandran N, Friedhoff A. Factors affecting the delay of antidepressant effect in responders to nortriptyline and phenelzine. Psychiatry Res 1989; 28(1): 1-9.

[2] Fava M, Rosenbaum JF, McGrath PJ, Stewart JW, Amsterdam JD, Quitkin FM. Lithium and tricyclic augmentation of fluoxetine treatment for resistant major depression: a double-blind, controlled study. Am J Psychiatry 1994; 151(9): 1372-4.

[3] Nemeroff CB. Evolutionary trends in the pharmacotherapeutic management of depression. J Clin Psychiatry [Review]. 1994; 55 (Suppl 3-15): discussion 6-7.

[4] Trivedi MH, Rush AJ, Wisniewski SR, et al. Evaluation of outcomes with citalopram for depression using measurement-based care in STAR*D: implications for clinical practice. Am J Psychiatry 2006; 163(1): 28-40.

[5] Spigset O, Martensson B. Fortnightly review: drug treatment of depression. BMJ [Review]. 1999 1; 318(7192): 1188-91.

[6] Anderson IM, Nutt DJ, Deakin JF. Evidence-based guidelines for treating depressive disorders with antidepressants: a revision of the 1993 British Association for Psychopharmacology guidelines. British Association for Psychopharmacology. J Psychopharmacol 2000; 14(1): 3-20.

[7] Wijkstra J, Lijmer J, Balk FJ, Geddes JR, Nolen WA Pharmacological treatment for unipolar psychotic depression: Systematic review and meta-analysis. Br J Psychiatry 2006; 188: 410-5. 
[8] Davidson JR, Connor KM. Bupropion sustained release: a therapeutic overview. J Clin Psychiatry [Review]. 1998; 59 (Suppl 4): 25-31.

[9] Stokes PE, Holtz A. Fluoxetine tenth anniversary update: the progress continues. Clin Ther 1997; 19(5): 1135-250.

[10] Riggs PD, Mikulich SK, Coffman LM, Crowley TJ. Fluoxetine in drug-dependent delinquents with major depression: an open trial. J Child Adolesc Psychopharmacol 1997; 7(2): 87-95.

[11] Nunes EV, Deliyannides D, Donovan S, McGrath PJ. The management of treatment resistance in depressed patients with substance use disorders. Psychiatr Clin North Am 1996; 19(2): 311-27.

[12] Akiskal HS, Mallya G. Criteria for the "soft" bipolar spectrum: treatment implications. Psychopharmacol Bull 1987; 23(1): 68-73.

[13] Akiskal HS. Dysthymic and cyclothymic depressions: therapeutic considerations. J Clin Psychiatry [Review]. 1994; 55 (Suppl): 4652 .

[14] Mendelson M, Freeman AM, Kaplan HI. Neurotic depressive reactions. Baltimore: Williams and Wilkins Co 1967.
[15] Ravindran AV, Bialik RJ, Lapierre YD. Therapeutic efficacy of specific serotonin reuptake inhibitors (SSRIs) in dysthymia. Can J Psychiatry 1994; 39(1): 21-6.

[16] Kramer PD. Listening to Prozac. New York: Penguin Book. 1993.

[17] The American Psychiatric Association. Diagnostic and Statistical Manual of Mental Disorders. $4^{\text {th }}$ ed. Washington: American Psychiatric Press 1994.

[18] McMorris T, Collard K, Corbett J, Dicks M, Swain JP. A test of the catecholamines hypothesis for an acute exercise-cognition interaction. Pharmacol Biochem Behav 2008; 89(1): 106-15.

[19] Simeon JG, Ferguson HB, Van Wyck Fleet J. Bupropion effects in attention deficit and conduct disorders. Can J Psychiatry 1986; 31(6): 581-5.

[20] Casat CD, Pleasants DZ, Van Wyck Fleet J. A double-blind trial of bupropion in children with attention deficit disorder. Psychopharmacol Bull 1987; 23(1): 120-2.

[21] Hosmer DW, Lemeshow S. Applied logistic regression. USA: Wiley 2000.

Received: February 03, 2013

(C) Shipman et al.; Licensee Bentham Open.

This is an open access article licensed under the terms of the Creative Commons Attribution Non-Commercial License (http://creativecommons.org/licenses/by-nc/3.0/) which permits unrestricted, non-commercial use, distribution and reproduction in any medium, provided the work is properly cited. 